\title{
Low segregation ratios in autosomal recessive disorders
}

The recent simultaneous publication of an account of a reduced segregation ratio in cartilage-hair hypoplasia $(\mathrm{CHH})$ in Finland ${ }^{1}$ and of one explanation for some examples of isolated cases of autosomal recessive (AR) diseases ${ }^{2}$ has led to a reconsideration of this interesting and important subject.

It is notable that a low segregration ratio has often been found in genetic studies of supposedly recessive diseases, such as those on chronic spinal muscular atrophy, ${ }^{3}$ osteogenesis imperfecta, ${ }^{4}$ and ataxia telangiectasia. ${ }^{5}$ Such unexpectedly low proportions of affected sibs of patients with presumed recessive diseases may have many causes which can be considered under the headings of parental behaviour, observer error, and biological factors.

\section{Parental behaviour}

Parents may be responsible, albeit often inadvertently, in three ways. Firstly, the affected child may have a different father from the other children in the sibship. Secondly, parents may not report earlier affected sibs, perhaps because of fear of stigmatisation, or alternatively earlier affected sibs may not have been diagnosed. This may be more likely to happen if many earlier sibs have been born in another less well developed country, and may account for the small proportion of earlier affected sibs (five out of 28) seen in Pakistani families whose index child with an AR disease was born in the UK. ${ }^{6}$

Thirdly, the parents may have been deterred from having further children after the first affected, even in the absence of genetic counselling. Such a deterrent effect was observed in families in which a child with phenylketonuria was diagnosed in a neonatal screening programme. ${ }^{7}$ During the period of ascertainment families with an affected child contained an excess of first affected among second or later born children and a deficit of affected first borns. It thus appeared that some families were deterred from having further children after their first affected child. A deterrent effect of this nature is likely to exist only for those conditions in which the symptoms manifest themselves sufficiently early and sufficiently seriously to influence the parents' subsequent plans for childbearing.

\section{Observer error}

Can geneticists erroneously produce a segregation ratio greater or lower than $0 \cdot 25$ ? Segrega- tion analysis is a notoriously difficult subject in which mode of ascertainment is critical. ${ }^{8}$ For example, analysis of published cases, in which there is likely to be a bias towards reporting familial cases, can easily lead to a ratio greater than $0 \cdot 25$. This also applies if no account is taken of the fact that even the most complete ascertainment is 'truncate' in that sibships in which both parents are carriers but which contain no affected cases are not included. The 'a priori' and 'maximum likelihood' methods of segregation analysis account for truncate ascertainment and should therefore give a more reliable estimate of the true ratio, but these methods rely on full ascertainment which is rarely achievable. However, in the presence of complete ascertainment geneticists can easily produce a lower than true segregation ratio by using an inappropriate method of analysis such as the 'single' or 'sib' method. ${ }^{8}$

\section{Biological factors}

Most interesting of all are the possible biological explanations for a low segregation ratio in a presumed AR disease. Several mechanisms can be considered.

\section{NON-PENETRANCE}

This has been suggested for $\mathrm{CHH}$ by Mäkitie in Finland ${ }^{1}$ and by McKusick et $a l^{9}$ who studied this condition in Old Order Amish. In the Finnish series there was complete ascertainment of $\mathrm{CHH}$ among children, but incomplete ascertainment in adults. Using truncate analysis, the number of affected sibs was significantly less than expected, and the best fit for the segregation ratio was $0 \cdot 203$. The 'single method', not unexpectedly, gave a much lower proportion of $0 \cdot 123$. The author agreed with McKusick et $a l^{9}$ who suggested that reduced penetrance in some homozygotes could explain the low proportion of affected sibs. The best evidence for such a phenomenon was mild $\mathrm{CHH}$ discovered radiologically in three Amish children who were presumed homozygotes as both their parents were affected. ${ }^{9}$ However, no possibly mild manifestations were found in the Finnish families. ${ }^{1}$ The disease is relatively common in Finland, 1 in 23000 live births, and so the finding of two instances of parental consanguinity and 20 out of 85 families who had interfamilial relationships is consistent with all cases having an autosomal recessive condition arising from a few heterozygous ancestors. The concept of reduced penetrance in 
a congenital autosomal recessive disease is unexpected, but it gains credence from the observation that a skeletal dysplasia in Ancon sheep also displays reduced penetrance. ${ }^{9}$

\section{EARLY LETHALITY}

In these studies of $\mathrm{CHH},{ }^{19}$ as in the study mentioned earlier on ataxia telangiectasia, ${ }^{5}$ there was no observable increased incidence of abortions or stillbirths, either of which could in theory account for a low proportion of affected sibs. However, pregnancy loss in utero need not always be recognised and early death because of homozygosity for a lethal gene closely linked to the $\mathrm{CHH}$ locus or to an ataxia telangiectasia locus is another possibility.

\section{GAMETE SELECTION (MEIOTIC DRIVE)}

Selection for or against gametes bearing a recessive gene could obviously result in a distorted segregation ratio. To our knowledge no examples of such selection have been documented in man.

\section{UNIPARENTAL DISOMY}

Molecular techniques have made it possible to identify several examples of uniparental disomy in man. Woods and Edwards ${ }^{2}$ have predicted that a small proportion of rare AR disease could be the result of uniparental isodisomy. This would be significant for individual families for whom there would be no recurrence and emphasises the importance of considering this explanation when counselling parents who have had an affected child with unusual additional features or who have had only one affected child in a very large sibship. However, in segregation analysis, uniparental isodisomy is likely to have only a small effect if many families are being studied, or if the condition is relatively common as applies to $\mathrm{CHH}$ in Finland.

\section{MONOSOMY OWING TO A DELETION}

The occurrence of a recessive allele on one chromosome, paired by a de novo deletion of the homologous region of the other parent's chromosome, is a rare cause of non-recurrent AR disease. Such a phenomenon is unlikely to have much effect on the segregation ratio of large family studies but is very important on an individual basis, since it provides a clue to the localisation of the disease gene. The occurrence of oculocutaneous albinism in some patients with 15q11-13 deletions was one of several clues leading to the isolation of the $P$ gene. ${ }^{1011}$

\section{GENETIC HETEROGENEITY}

Probably the most common explanation for a low segregation ratio is that the disease is not always recessively inherited, with some cases being the result of new dominant mutations and some examples of recurrence in a sibship resulting from gonadal mosaicism. It is therefore wise to check if the parental consanguinity rate equals that expected on the basis of $A R$ inheritance and the known disease frequency. ${ }^{5}$ Such genetic heterogeneity is unlikely to be the explanation for $\mathrm{CHH}$ where in the Amish, and probably also in Finland, present day cases originate from a few heterozygous ancestors. However, in more heterogeneous populations an admixture with new dominant mutations could well occur. For example, it is now recognised that most cases of type II osteogenesis imperfecta, a disorder once believed to show $\mathrm{AR}$ inheritance, result from new heterozygous (dominant) mutations in one of the type I collagen genes. ${ }^{12}$

Four other disorders are worth considering in this respect: achondrogenesis, retinitis pigmentosa, chronic spinal muscular atrophy, and ataxia telangiectasia. There are several types of achondrogenesis, some of which show AR inheritance, whereas the mildest forms result from new dominant mutations in type II collagen. ${ }^{13}$ Similarly retinitis pigmentosa is genetically heterogeneous, with mutations in the rhodopsin gene causing a severe AR condition as well as being responsible for some dominant forms. ${ }^{14}$ It may well be that some dominant types of chronic spinal muscular atrophy result from heterozygous mutations of the gene at 5q11.2-13.3, which causes the acute and chronic forms. (However, some dominant types do not map to this locus. ${ }^{15}$ ) The explanation of the low segregation ratio in ataxia telangiectasia is not clear but could well be because of admixture with dominant mutations. ${ }^{5}$ Note that the very low fertility of patients with chronic spinal muscular atrophy and ataxia telangiectasia means that transmission of disease from affected parent to affected child is rarely observed. Nevertheless, the hypothesis that some cases are the result of new dominant mutations should not be ignored.

\section{Conclusion}

A low segregation ratio in a supposedly AR disorder is an important observation. For the geneticist this should trigger off a search for alternative explanations leading ultimately to better understanding of the underlying disease mechanism(s). For the individual family the implications could be enormous. There is a cruel irony in parents being deterred from further child bearing by a quoted recurrence risk of 1 in 4 , only to be presented in years to come by an affected grandchild born to their own affected child whose disorder has arisen as a consequence of a new dominant mutation. It is therefore important not to ignore a sib segregation ratio that is less than $0 \cdot 25$. The investigator's question should not be "is this proportion consistent with $0 \cdot 25$ ?" but rather "what is the range of this observed proportion, and what are its likely mechanisms?"

SARAH BUNDEY Department of Clinical Genetics, Birmingham Maternity Hospital, Edgbaston, Birmingham B15 2TG, UK. 
I D YOUNG

Department of Clinical Genetics, City Hospital Hucknall Road,

Nottingham NG5 $1 P B, U K$.

1 Mäkitie O. Cartilage-hair hypoplasia in Finland: epidemiological and genetic aspects of 107 patients. $\mathcal{F}$ Med Genet 1992;29:652-5.

2 Woods CG, Edwards JH. The need for care in the use of linkage analysis for genetic diagnosis in small families, with particular reference to uniparental disomy (letter). with particular reference to uniparen

3 Pearn J, Bundey S, Carter CO, Wilson J, Gardner-Medwin D, Walton JN. A genetic study of subacute and chronic spinal muscular atrophy in childhood. $f$ Neurol Sci 1978;37:227-48.

4 Thompson EM, Young ID, Hall CM, Pembrey ME. Recurrence risks and prognosis in severe sporadic osteogenesis imperfecta. F Med Genet 1987;24:390-405.

5 Woods CG, Bundey SE, Taylor AMR. Unusual features in the inheritance of ataxia telangiectasia. Hum Genet 1990;84:555-62.

6 Bundey S, Alam H. A five-year prospective study of the health of children in different ethnic groups with particular reference to the effect of inbreeding. Eur $\mathcal{F}$ Hum Genet (in press).

7 Brookfield JFY, Pollitt RJ, Young ID. Family size limitation: a method for demonstrating recessive inheritance. tation: a method for demonst
$\mathcal{H}$ Med Genet $1988 ; 25: 181-5$.
8 Emery AEH. Methodology in medical genetics. 2nd ed. Edinburgh: Churchill Livingstone, 1986:37-54. 9 McKusick VA, Eldridge R, Hostetler JA, Ruangwit U, Egeland JA. Dwarfism in the Amish. II. Cartilage-hair hypoplasia. In: McKusick VA, ed. Medical genetic studies of the Amish. Baltimore: Johns Hopkins University Press, 1978:231-72.

10 Gardner JM, Nakatsu Y, Gondo Y, et al. The mouse pinkeyed dilution gene: association with human Prader-Willi and Angelman syndromes. Science 1992;257:1121-4.

11 Rinchick EM, Bultman SJ, Horsthemke B, et al. A gene for the mouse pink-eyed dilution locus and for human type II oculocutaneous albinism. Nature 1993:361:72-6.

12 Prockop DJ, Constantinou CD, Dombrowski KE, et al. Type I procollagen: the gene-protein system that harbors most of the mutations causing osteogenesis imperfecta most of the mutations causing osteogenesis imperfecta nective tissue. Am $\mathcal{J}$ Med Genet 1989;34:60-7.

13 Godfrey M, Keene DR, Blank E, et al. Type II achondrogenesis-hypochondrogenesis: morphologic and immunohistopathologic studies. Am $\mathcal{f}$ Hum Genet 1988;43:894-903.

14 Rosenfield PJ, Cowley GS, McGee TL, Sandberg MA, Berson EL, Dryja TP. A null mutation in the rhodopsin gene causes rod photoreceptor dysfunction and autosomal recessive retinitis pigmentosa. Nature Genet 1992;1:20913.

15 Kausch K, Müller CR, Grimm T, et al. No evidence for linkage of autosomal dominant proximal spinal muscular atrophies to chromosome 5q markers. Hum Genet atrophies to ch 